Committee of the C.I.A.O., and that responsibility for the secretariat of the Committee be undertaken by the section of Geography of IFAN.

That the Conference considers necessary, not only an increased production of maps and population censuses for West Africa, but also the adoption of such a standardized system of procedure as may be most suitable from the point of view of scientific accuracy and of the purposes in view.

That the widest publicity be given to the proposal of Lt. Teixeira da Mota concerning a revision of the orthography of place-names in West Africa, and that Governments and competent authorities be invited to consider the corrections formulated.

That, in order to advance knowledge of early navigation on the West coasts of Africa, excavations should be systematically undertaken by the Departments of Antiquities of the countries concerned, in the coastal islands and favourable sites at the mouths of rivers south of the Atlas mountains.

That studies concerned with the effects of contacts between different cultures be developed in accordance with an extensive and systematic scheme, the results obtained in each area being examined and compared with those of other areas at subsequent meetings of C.I.A.O.

The Conference also expressed the hope that it might be possible for the next meeting to be held in a British West African territory. Since the Bissao meeting the Government of Nigeria and the British Colonial Office have agreed in principle to invite the third Conference to meet in Nigeria, and negotiations to that effect are in progress.

Further information concerning the C.I.A.O. can be obtained from its Permanent Secretary, Professor Th. Monod, Director, Institut Français d'Afrique Noire, Dakar, French West Africa; and with regard to the Bissao meeting from Professor A. A. Mendes Correia, 88 Junqueira, Lisbon, Portugal.

The International African Institute will be happy to give members any further information in its possession, and announcements with regard to the third Conference will be published in Africa as soon as they are available.

DARYLL FORDE

\title{
Migrant Labour and Tribal Life
}

Professor Schapera writes: In his review of my book, Migrant Labour and Tribal Life (Africa, April I948, pp. I43 ff.), Mr. A. Sandilands correctly describes Table XI as 'very inaccurate', but his comment, as it stands, suggests that I am responsible for the inaccuracy. In fact, had he read more carefully the paragraphs immediately preceding and following the Table, he would have seen it stated explicitly (a) that the figures given in the Table are derived primarily from returns submitted by district officers about the distribution of Native manpower, both in Bechuanaland and elsewhere, and $(b)$ that owing to the methods of collection and sampling employed, especially in the Ngwato Reserve, those figures 'cannot be accepted unreservedly' (op. cit., p. 35). My own estimates are given in Table XII (pp. $36 \mathrm{ff}$.), which also includes 'the correct figures . . . of the territory's war-effort' that Mr. Sandilands implies I have omitted. 